\title{
Mycobacterium avium complex
}

National Cancer Institute

\section{Source}

National Cancer Institute. Mycobacterium avium complex. NCI Thesaurus. Code C76368.

A group of very similar Mycobacteria consisting of Mycobacterium avium and M.

intracellulare. 